\title{
The Antibacterial Efficacy of Biopure MTAD in Root Canal Contaminated with Enterococcus faecalis
}

\author{
Blerim Kamberi, ${ }^{1}$ Donika Bajrami, ${ }^{1}$ Miranda Stavileci, ${ }^{1}$ Shuhreta Omeragiq, ${ }^{2}$ \\ Fatmir Dragidella, ${ }^{3}$ and Ferit Koçani ${ }^{1}$ \\ ${ }^{1}$ Department of Dental Pathology and Endodontics, University Dentistry Clinical Center of Kosovo, 10000 Prishtina, Kosovo \\ ${ }^{2}$ Department of Microbiology, Directory of Water High Quality, Prishtina, Kosovo \\ ${ }^{3}$ Department of Periodontology and Oral Medicine, University Dentistry Clinical Center of Kosovo, 10000 Prishtina, Kosovo
}

Correspondence should be addressed to Blerim Kamberi, blerimkamberi63@hotmail.com

Received 18 April 2012; Accepted 30 July 2012

Academic Editors: F. Cairo, D. Drake, and J. Virtanen

Copyright ( $) 2012$ Blerim Kamberi et al. This is an open access article distributed under the Creative Commons Attribution License, which permits unrestricted use, distribution, and reproduction in any medium, provided the original work is properly cited.

\begin{abstract}
Aim. The purpose of this in vitro study was to assess the antimicrobial efficacy of Biopure MTAD against E. faecalis in contaminated root canals. Materials and Methods. Forty-two single rooted extracted human teeth were inoculated with E. faecalis and incubated for four weeks. The samples were divided in two control and five experimental groups irrigated with $1.5 \%$ sodium hypochlorite solution ( $\mathrm{NaOCl}$ ); $3 \% \mathrm{NaOCl}$; BioPure MTAD; $1.5 \% \mathrm{NaOCl} / 17 \%$ EDTA; or 3\% NaOCl/17\% EDTA. After a one-week incubation, complete disinfection was confirmed by the absence of turbidity in the incubation media. Dentin shavings were taken from samples with no turbidity to verify whether E. faecalis was present in dentin tubules. Results were analyzed statistically using Fisher's exact test, with the level of significance set at $P<0.05$. Results. Statistical analysis of the data obtained at Day 7 and after dentin shaving analysis showed that BioPure MTAD had significantly greater antibacterial activity than $1.5 \% \mathrm{NaOCl}, 1.5 \% \mathrm{NaOCl} / 17 \% \mathrm{EDTA}$ and 3\% NaOCl$/ 17 \%$ EDTA. No significant difference was detected between MTAD and 3\% NaOCl. Conclusions. These findings suggest that BioPure MTAD possesses superior bactericidal activity compared with $\mathrm{NaOCl}$ and EDTA against E. faecalis.
\end{abstract}

\section{Introduction}

The major cause of endodontic failure is the survival of microorganisms in the root-filled tooth. Numerous authors have identified $E$. faecalis as the predominant microorganism found in root-treated canals displaying persistent periapical disease $[1,2]$. The difficulty in eliminating E. faecalis from the root canal is due to its ability to adapt to environmental changes while retaining its pathogenicity [3]. Previous studies report a prevalence of E. faecalis ranging from 24$77 \%$ in teeth with failed endodontic treatment [4-8].

Endodontic infections are currently treated by mechanical debridement followed by chemical disinfection. Irrigants are used during the endodontic treatment to flush out loose debris, lubricate the dentinal walls, dissolve organic matter in the canal, and provide antimicrobial activity [9]. Sodium hypochlorite $(\mathrm{NaOCl})$, at concentrations between $0.5-6 \%$, is the most popular irrigating solution due to its antimicrobial activity and its ability to dissolve necrotic tissue [10]. However, sodium hypochlorite does not disinfect the entire root canal system, does not remove the smear layer from the dentinal walls, and is highly destructive when it comes into contact with the periapical tissues and gingiva [11]. In contrast, ethylenediaminetetraacetic acid (EDTA) has low or no antibacterial activity, but effectively removes the smear layer by affecting the inorganic component of the dentine. By facilitating the removal of infected tissue, EDTA contributes to the elimination of bacteria in the root canal [12]. Thus, to facilitate root canal disinfection, it is recommended that an irrigant containing both $\mathrm{NaOCl}$ and EDTA be used [11].

Torabinejad et al. [13] have reported the development of new irrigants for use in canal disinfection and smear layer removal, including BioPure MTAD (Dentsply, Tulsa, OK), a mixture of a tetracycline isomer [doxycycline], an acid [citric acid], and a detergent [Tween 80]. The doxycycline present 
in MTAD has high binding affinity for dentine, allowing for a prolonged antibacterial effect [14]. BioPure MTAD has been recommended as a final rinse irrigant because of its antimicrobial properties and its ability to remove the smear layer $[11,13,15-17]$. It is also less cytotoxic than most endodontic medicaments, including eugenol, hydrogen peroxide (3\%), EDTA, and calcium hydroxide paste [1518]. However, it has also been reported that BioPure MTAD (Dentsply) may not be effective against E. faecalis [1921]. Therefore, the purpose of this study was to assess the antimicrobial efficacy of BioPure MTAD against $E$. faecalis compared to conventional endodontic irrigants.

\section{Materials and Methods}

The methodology used in the present study was modified slightly from that described previously by Shabahang and Torabinejad [16]. Forty-two single-rooted extracted human teeth were used for this study. Samples were stored in water to avoid dehydration before use. After gaining access, the pulp was removed, irrigated with distilled water and all teeth were sterilized in an autoclave at $121^{\circ} \mathrm{C}$ (Sterilizatoren $\mathrm{GmbH}$, Oiching, Germany).

Pure cultures of E. faecalis (ATCC 29212 OXOID, Hampshire, UK) were incubated overnight in blood heart infusion broth (BHI-Oxoid LTD., Wade Road, Basingstoke, Hampshire, UK) with a preparation of $1 \times 10^{8}$ bacteria in $125 \mathrm{~mL}$ broth sufficient to prepare five experimental tubes. Teeth were immersed in inoculum and incubated at $37^{\circ} \mathrm{C}$ for four weeks in aerobic conditions in an incubator (INNOVENS 53, Jouan, France). This incubation period was sufficient for E. faecalis to invade the dentinal tubules. Culture media was refreshed every third day to maintain bacteria levels. Each tooth was sampled with paper points, from external and internal surface, inoculated on BHI plates to confirm the presence of infection.

Following four weeks of infection, samples were divided into seven groups: two control and five experimental groups. Working length was established by using \#10 K-file to penetrate the apical foramen and then pulled back $1 \mathrm{~mm}$. The teeth were manually instrumented with Flexo Files (Dentsply, Maillefeller Ballaigues, Switzerland) up to size \#40 using a passive step-back technique. During cleaning and shaping, rigorous aseptic techniques were followed using sterile gloves and pliers. In the positive control group, irrigation was performed using distilled water. In the negative control group, the irrigant was also distilled water, but irrigation was followed by a period of autoclaving. Sterilization of these samples ensured that contamination of the working field did not occur. The remaining teeth were divided into five experimental groups, as detailed in Table 1.

Following preparation, each tooth was immersed in $2 \mathrm{~mL}$ of BHI and vortexed for $15 \mathrm{~s}$. Teeth were then transferred into tubes containing fresh $\mathrm{BHI}$ and incubated for one week at $37^{\circ} \mathrm{C}$ under aerobic conditions. Complete disinfection was confirmed by the absence of media turbidity at a oneweek period. Samples that showed turbidity were classified as infected, and the presence of bacteria was identified on BHI agar plates, and observed with microscope to identify Grampositive cocci in chains.

To determine the presence of bacteria in the dentinal tubule, dentin shavings were taken with sterile carbide bur no. 3. Shavings were taken from those samples that exhibited no turbidity to verify whether $E$. faecalis was present in the dentinal tubules. The teeth and dentin shavings were cultivated to determine the presence or absence of E. faecalis. Turbidity in cultivated solutions indicated the presence of E. faecalis. Shavings were collected on BHI agar plates and incubated for $48 \mathrm{~h}$.

Results were analyzed by Fisher's exact test, with the level of significance set at $P<0.05$.

\section{Results}

Turbidity was evident in all of the positive control samples, but in none of the negative controls. The presence of turbidity in test samples is summarized in Table 2. After one week of incubation, turbidity was evident to some degree in each of the groups treated with $\mathrm{NaOCl}$ or $\mathrm{NaOCl}+$ EDTA. In contrast, none of the samples treated with BioPure MTAD were visibly infected. When dentine shavings were incubated in BHI broth, a single sample in each of the five groups was infected with $E$. faecalis.

Statistical analysis of the total number of infected samples in each group using Fisher's exact test showed significant differences between BioPure MTAD and 1.5\% NaOCl, 1.5\% $\mathrm{NaOCl} / 17 \%$ EDTA and $3 \% \mathrm{NaOCl} / 17 \%$ EDTA $(P=0.008$ for each comparison), but no significant difference between BioPure MTAD and $3 \% \mathrm{NaOCl}(P=0.242)$. Because each group had a single sample (out of six) found to be infected in the dentinal tubules, this difference can be attributed entirely to differences in the rate of infection after the one-week incubation. Indeed, Fisher's exact test found near-identical results when analyzing these rates specifically $(P=0.008$ for BioPure MTAD versus $1.5 \% \mathrm{NaOCl}, 1.5 \% \mathrm{NaOCl} / 17 \%$ EDTA, $3 \% \mathrm{NaOCl} / 17 \%$ EDTA; $P=0.227$ for BioPure MTAD versus $3 \% \mathrm{NaOCl}$.

\section{Discussion}

Enterococcus faecalis is commonly found in failed roottreated canals [22], due mainly to its resistance to chemomechanical procedures [6] and intracanal medication such as calcium hydroxide [23]. In our experiments, positive control samples showed that distilled water is totally ineffective at eliminating E. faecalis. Furthermore, negative control samples confirmed that the incubation environment used during the experiment was not contaminated. We chose several irrigants to evaluate their efficacy in eliminating $E$. faecalis from the root canal system. $\mathrm{NaOCl}$, in addition to its excellent anti-bacterial properties, is known to be cytotoxic at higher concentrations, so we evaluated this irrigant at both low (1.5\%) and high (3\%) concentrations. Our results demonstrate that irrigation with $\mathrm{NaOCl}$, even at the high concentration, eliminated E. faecalis in only half of the samples. This lack of efficacy of $\mathrm{NaOCl}$ in consistently 
TABLE 1: Irrigation protocol.

\begin{tabular}{lcccc}
\hline Group & No. of teeth & Irrigation during cleaning and shaping & Final rinse & Immersion \\
\hline Positive control & 6 & Distilled water & $\mathrm{dH}_{2} \mathrm{O}$ & $\mathrm{dH}_{2} \mathrm{O}$ \\
Negative control & 6 & Distilled water & $\mathrm{dH}_{2} \mathrm{O}$ and autoclave & $\mathrm{dH} \mathrm{H}_{2} \mathrm{O}$ \\
A & 6 & $1.5 \% \mathrm{NaOCl}, 1 \mathrm{~mL}$ after each file & $1.5 \% \mathrm{NaOCl}, 5 \mathrm{~mL}$ & $1.5 \% \mathrm{NaOCl}, 5 \mathrm{~min}$ \\
B & 6 & $3 \% \mathrm{NaOCl}, 1 \mathrm{~mL}$ after each file & $3 \% \mathrm{NaOCl}, 5 \mathrm{~mL}$ & $3 \% \mathrm{NaOCl}, 5 \mathrm{~min}$ \\
C & 6 & $1.5 \% \mathrm{NaOCl}, 1 \mathrm{~mL}$ after each file & $\mathrm{MTAD}, 5 \mathrm{~mL}$ & $\mathrm{MTAD}, 5 \mathrm{~min}$ \\
D & 6 & $1.5 \% \mathrm{NaOCl}, 1 \mathrm{~mL}$ after each file and EDTA $17 \%, 1 \mathrm{~min}$ & $1.5 \% \mathrm{NaOCl}, 5 \mathrm{~mL}$ & $1.5 \% \mathrm{NaOCl}, 5 \mathrm{~min}$ \\
E & 6 & $3 \% \mathrm{NaOCl}, 1 \mathrm{~mL}$ after each file and EDTA $17 \%, 1 \mathrm{~min}$ & $3 \% \mathrm{NaOCl}, 5 \mathrm{~mL}$ & $3 \% \mathrm{NaOCl}, 5 \mathrm{~min}$ \\
\hline
\end{tabular}

TABLE 2: Presence of E. faecalis in tooth samples treated with different endodontic irrigants.

\begin{tabular}{lcccc}
\hline Groups & No. of Samples & \multicolumn{3}{c}{ Growth } \\
One week & Dentin shavings & Total \\
\hline Positive & 6 & 6 & 6 & 6 \\
Negative & 6 & 0 & 0 & 0 \\
A & 6 & 5 & 1 & 6 \\
B & 6 & 2 & 1 & 3 \\
C & 6 & 0 & 1 & 1 \\
D & 6 & 5 & 1 & 6 \\
E & 6 & 5 & 1 & 6 \\
\hline
\end{tabular}

disinfecting root canals is in agreement with results from previous investigations. A clinical study by Sjörgren et al. [24] concluded that $40 \%$ of root canal systems remain infected following irrigation with $0.5 \% \mathrm{NaOCl}$. In another study, SiqueiraJr et al. [10] investigated the ability of $4 \%$ $\mathrm{NaOCl}$ solution, used in various irrigation protocols, to eliminate $E$. faecalis from the root canal system and found that after irrigation with $4 \% \mathrm{NaOCl} 30-40 \%$ of root canal systems remained infected with $E$. faecalis.

The smear layer is known to impede the penetration of antimicrobial agents into dentinal tubules [25]. We therefore included Groups D and E that were irrigated with $1.5 \%$ and $3 \% \mathrm{NaOCl}$, but were additionally treated with $17 \%$ EDTA prior to the final incubation with $\mathrm{NaOCl}$. This removes the smear layer, giving $\mathrm{NaOCl}$ improved access to the dentinal tubules. However, in accordance with previous reports [15, 16], our results demonstrated that smear layer removal by this method does not increase the antimicrobial effect of $\mathrm{NaOCl}$.

In recent years, several studies have focused on evaluating the effectiveness of BioPure MTAD as a root canal irrigant against E. faecalis. Newberry et al. [26] determined the antimicrobial effect of BioPure MTAD as a final irrigant on eight strains of E. faecalis. After irrigating with $1.3 \% \mathrm{NaOCl}$, the root canal and external surfaces were exposed to BioPure MTAD for $5 \mathrm{~min}$. Roots or dentin shavings were cultured to determine the growth of E. faecalis, and results showed that this treatment regimen was completely effective at eliminating the growth of seven of the eight E. faecalis strains. Furthermore, Davis et al. [27] used in vitro experiments to show that $2 \%$ chlorhexidine and $5.25 \% \mathrm{NaOCl}$ both exhibited less antimicrobial efficacy against E. faecalis than
BioPure MTAD, demonstrating that BioPure MTAD is a viable medicament against $E$. faecalis. In another study, Mohammadi and Shahriari [28] compared the antimicrobial effect of Biopure MTAD, 2\% chlorhexidine and $2.6 \% \mathrm{NaOCl}$ on E. faecalis in human root dentin. Their findings showed the BioPure MTAD was more effective than the other solutions, and was retained in the root canal dentin for at least 28 days. These findings are consistent with our own results (Group C) and those of other researchers [15, 16, 2932] who have reported the superior efficacy of BioPure MTAD against $E$. faecalis.

However, our results are contrary to some other reports on the antimicrobial effects of irrigants. A study by Kho and Baumgartner [20] compared the antimicrobial efficacy of irrigation with $1.3 \% \mathrm{NaOCl} / \mathrm{Biopure} \mathrm{MTAD}$ with that of irrigation with $5.25 \% \mathrm{NaOCl} / 15 \%$ EDTA in the apical $5 \mathrm{~mm}$ of roots infected with E. faecalis, and found no difference between these treatments. In addition, Baumgartner et al. [21] found no growth of E. faecalis in root canals irrigated with $5.25 \% \mathrm{NaOCl} / 15 \%$ EDTA, while $50 \%$ of the canals irrigated with $1.3 \% \mathrm{NaOCl} /$ Biopure MTAD demonstrated growth of E. faecalis, a difference that was statistically significant. Our results are also in disagreement with those of Dunavant et al. [19], Giardino et al. [33], Clegg et al. [34], Ruff et al. [35], and Krause et al. [36], each of whom showed that $\mathrm{NaOCl}$ was more effective than BioPure MTAD at eliminating E. faecalis. These differences ensure that the efficacy of BioPure MTAD remains somewhat controversial, although are probably in part explained by methodological differences such as alternative microbial sampling procedures or deviation from the manufacturer's usage recommendations when using BioPure MTAD.

\section{Conclusions}

Our findings suggest that BioPure MTAD possesses superior bactericidal activity compared with $\mathrm{NaOCl}$ and EDTA against E. faecalis in contaminated root canals. However, further clinical studies are required to confirm the in vivo antimicrobial effects of this and other endodontic medicaments.

\section{Disclosure}

This paper is approved by all the coauthors. Also, this paper has the approval of the institution. 


\section{Acknowledgment}

The authors wish to thank Department of Microbiology, Directory of Water High Quality, Prishtina, Kosovo for their involvement and support of the present study.

\section{References}

[1] H. H. Hancock, A. Sigurdsson, M. Trope, and J. Moiseiwitsch, "Bacteria isolated after unsuccessful endodontic treatment in a North American population," Oral Surgery, Oral Medicine, Oral Pathology, Oral Radiology, and Endodontics, vol. 91, no. 5, pp. 579-586, 2001.

[2] J. F. Siqueira Jr and I. N. Rôças, "Exploiting molecular methods to explore endodontic infections: part 2-Redefining the endodontic microbiota," Journal of Endodontics, vol. 31, no. 7, pp. 488-498, 2005.

[3] C. H. Stuart, S. A. Schwartz, T. J. Beeson, and C. B. Owatz, "Enterococcus faecalis: its role in root canal treatment failure and current concepts in retreatment," Journal of Endodontics, vol. 32, no. 2, pp. 93-98, 2006.

[4] G. Sundqvist, D. Figdor, S. Persson, and U. Sjögren, "Microbiologic analysis of teeth with failed endodontic treatment and the outcome of conservative re-treatment," Oral Surgery, Oral Medicine, Oral Pathology, Oral Radiology, and Endodontics, vol. 85, no. 1, pp. 86-93, 1998.

[5] A. Molander, C. Reit, G. Dahlén, and T. Kvist, "Microbiological status of root-filled teeth with apical periodontitis," International Endodontic Journal, vol. 31, no. 1, pp. 1-7, 1998.

[6] V. Peciuliene, A. H. Reynaud, I. Balciuniene, and M. Haapasalo, "Isolation of yeasts and enteric bacteria in rootfilled teeth with chronic apical periodontitis," International Endodontic Journal, vol. 34, no. 6, pp. 429-434, 2001.

[7] E. T. Pinheiro, B. P. F. A. Gomes, C. C. R. Ferraz, E. L. R. Sousa, F. B. Teixeira, and F. J. Souza-Filho, "Microorganisms from canals of root-filled teeth with periapical lesions," International Endodontic Journal, vol. 36, no. 1, pp. 1-11, 2003.

[8] B. P. F. A. Gomes, E. T. Pinheiro, C. R. Gadê-Neto et al., "Microbiological examination of infected dental root canals," Oral Microbiology and Immunology, vol. 19, no. 2, pp. 71-76, 2004.

[9] J. F. Siqueira Jr, I. N. R $\hat{\jmath}$ ças, S. R. Santos, K. C. Lima, F. A. Magalhães, and M. de Uzeda, "Efficacy of instrumentation techniques and irrigation regimens in reducing the bacterial population within root canals.," Journal of Endodontics, vol. 28, no. 3, pp. 181-184, 2002.

[10] J. F. Siqueira Jr, A. G. Machado, R. M. Silveira, H. P. Lopes, and M. De Uzeda, "Evaluation of the effectiveness of sodium hypochlorite used with three irrigation methods in the elimination of Enterococcus faecalis from the root canal, in vitro," International Endodontic Journal, vol. 30, no. 4, pp. 279-282, 1997.

[11] M. Torabinejad, S. Shabahang, and K. Bahjri, "Effect of MTAD on postoperative discomfort: a randomized clinical trial," Journal of Endodontics, vol. 31, no. 3, pp. 171-176, 2005.

[12] M. Haapasalo, T. Udnæs, and U. Endal, "Persistent, recurrent, and acquired infection of the root canal system posttreatment," Endodontic Topics, vol. 6, no. 1, pp. 29-56, 2003.

[13] M. Torabinejad, A. A. Khademi, J. Babagoli et al., "A new solution for the removal of the smear layer," Journal of Endodontics, vol. 29, no. 3, pp. 170-175, 2003.

[14] T. K. Machnick, M. Torabinejad, C. A. Munoz, and S. Shabahang, "Effect of MTAD on flexural strength and modulus of elasticity of dentin," Journal of Endodontics, vol. 29, no. 11, pp. 747-750, 2003.

[15] M. Torabinejad, S. Shabahang, R. M. Aprecio, and J. D. Kettering, "The antimicrobial effect of MTAD: an in vitro investigation," Journal of Endodontics, vol. 29, no. 6, pp. 400403, 2003.

[16] S. Shabahang and M. Torabinejad, "Effect of MTAD on Enterococcus faecalis-contaminated root canals of extracted human teeth," Journal of Endodontics, vol. 29, no. 9, pp. 576$579,2003$.

[17] S. Shabahang, M. Pouresmail, and M. Torabinejad, "In vitro antimicrobial efficacy of MTAD and sodium hypochlorite," Journal of Endodontics, vol. 29, no. 7, pp. 450-452, 2003.

[18] W. Zhang, M. Torabinejad, and Y. Li, "Evaluation of cytotoxicity of MTAD using the MTT-tetrazolium method," Journal of Endodontics, vol. 29, no. 10, pp. 654-657, 2003.

[19] T. R. Dunavant, J. D. Regan, G. N. Glickman, E. S. Solomon, and A. L. Honeyman, "Comparative evaluation of endodontic irrigants against Enterococcus faecalis biofilms," Journal of Endodontics, vol. 32, no. 6, pp. 527-531, 2006.

[20] P. Kho and J. C. Baumgartner, "A comparison of the antimicrobial efficacy of $\mathrm{NaOCl} /$ Biopure $\mathrm{MTAD}$ versus $\mathrm{NaOCl} / \mathrm{EDTA}$ against Enterococcus faecalis," Journal of Endodontics, vol. 32, no. 7, pp. 652-655, 2006.

[21] J. C. Baumgartner, S. Johal, and J. G. Marshall, "Comparison of the antimicrobial efficacy of $1.3 \% \mathrm{NaOCl} /$ BioPure MTAD to $5.25 \% \mathrm{NaOCl} / 15 \%$ EDTA for root canal irrigation," Journal of Endodontics, vol. 33, no. 1, pp. 48-51, 2007.

[22] I. N. Rôças, J. F. Siqueira Jr, and K. R. N. Santos, "Association of Enterococcus faecalis with different forms of periradicular diseases," Journal of Endodontics, vol. 30, no. 5, pp. 315-320, 2004.

[23] M. Evans, J. K. Davies, G. Sundqvist, and D. Figdor, "Mechanisms involved in the resistance of Enterococcus faecalis to calcium hydroxide," International Endodontic Journal, vol. 35, no. 3, pp. 221-228, 2002.

[24] U. Sjögren, D. Figdor, S. Persson, and G. Sundqvist, "Influence of infection at the time of root filling on the outcome of endodontic treatment of teeth with apical periodontitis," International Endodontic Journal, vol. 30, no. 5, pp. 297-306, 1997.

[25] R. M. Love, "Enterococcus faecalis-a mechanism for its role in endodontic failure," International Endodontic Journal, vol. 34, no. 5, pp. 399-405, 2001.

[26] B. M. Newberry, S. Shabahang, N. Johnson, R. M. Aprecio, and M. Torabinejad, "The antimicrobial effect of biopure MTAD on eight strains of Enterococcus faecalis: an in vitro investigation," Journal of Endodontics, vol. 33, no. 11, pp. 13521354, 2007.

[27] J. M. Davis, J. Maki, and J. K. Bahcall, "An in vitro comparison of the antimicrobial effects of various endodontic medicaments on Enterococcus faecalis," Journal of Endodontics, vol. 33, no. 5, pp. 567-569, 2007.

[28] Z. Mohammadi and S. Shahriari, "Residual antibacterial activity of chlorhexidine and MTAD in human root dentin in vitro." Journal of Oral Science, vol. 50, no. 1, pp. 63-67, 2008.

[29] I. Portenier, T. Waltimo, D. Ørstavik, and M. Haapasalo, "Killing of Enterococcus faecalis by MTAD and chlorhexidine digluconate with or without cetrimide in the presence or absence of dentine powder or BSA," Journal of Endodontics, vol. 32, no. 2, pp. 138-141, 2006.

[30] M. J. Royal, A. E. Williamson, and D. R. Drake, "Comparison of $5.25 \%$ sodium hypochlorite, MTAD, and $2 \%$ chlorhexidine in the rapid disinfection of polycaprolactone-based root canal 
filling material," Journal of Endodontics, vol. 33, no. 1, pp. 4244, 2007.

[31] J. Ghoddusi, A. Rohani, T. Rashed, P. Ghaziani, and M. Akbari, "An evaluation of microbial leakage after using MTAD as a final irrigation," Journal of Endodontics, vol. 33, no. 2, pp. 173176, 2007.

[32] F. R. Tay, N. Hiraishi, G. S. Schuster et al., "Reduction in antimicrobial substantivity of MTAD after initial sodium hypochlorite irrigation," Journal of Endodontics, vol. 32, no. 10, pp. 970-975, 2006.

[33] L. Giardino, E. Ambu, E. Savoldi, R. Rimondini, C. Cassanelli, and E. A. Debbia, "Comparative evaluation of antimicrobial efficacy of sodium hypochlorite, MTAD, and tetraclean against Enterococcus faecalis biofilm," Journal of Endodontics, vol. 33, no. 7, pp. 852-855, 2007.

[34] M. S. Clegg, F. J. Vertucci, C. Walker, M. Belanger, and L. R. Britto, "The effect of exposure to irrigant solutions on apical dentin biofilms in vitro," Journal of Endodontics, vol. 32, no. 5, pp. 434-437, 2006.

[35] M. L. Ruff, S. B. McClanahan, and B. S. Babel, "In vitro antifungal efficacy of four irrigants as a final rinse," Journal of Endodontics, vol. 32, no. 4, pp. 331-333, 2006.

[36] T. A. Krause, F. R. Liewehr, and C. L. Hahn, "The antimicrobial effect of MTAD, sodium hypochlorite, doxycycline, and citric acid on Enterococcus faecalis," Journal of Endodontics, vol. 33, no. 1, pp. 28-30, 2007. 


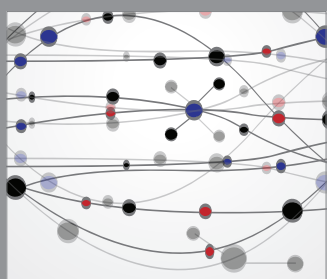

The Scientific World Journal
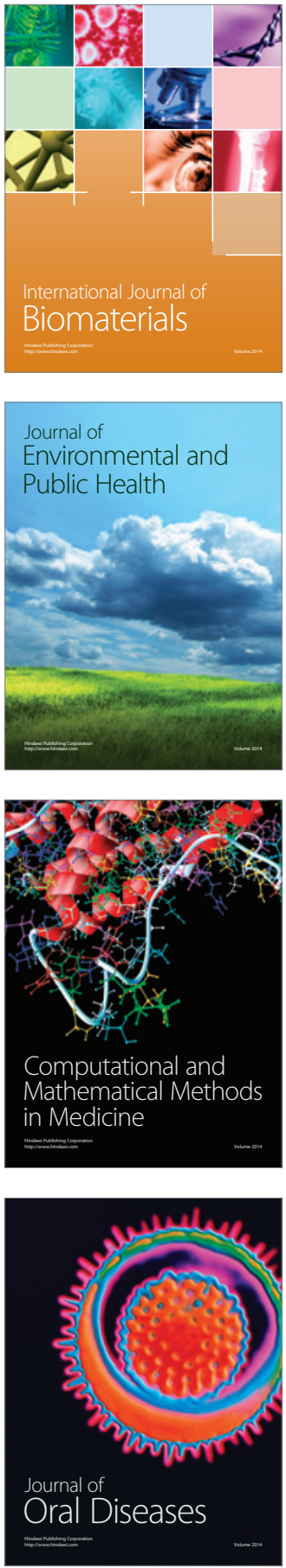
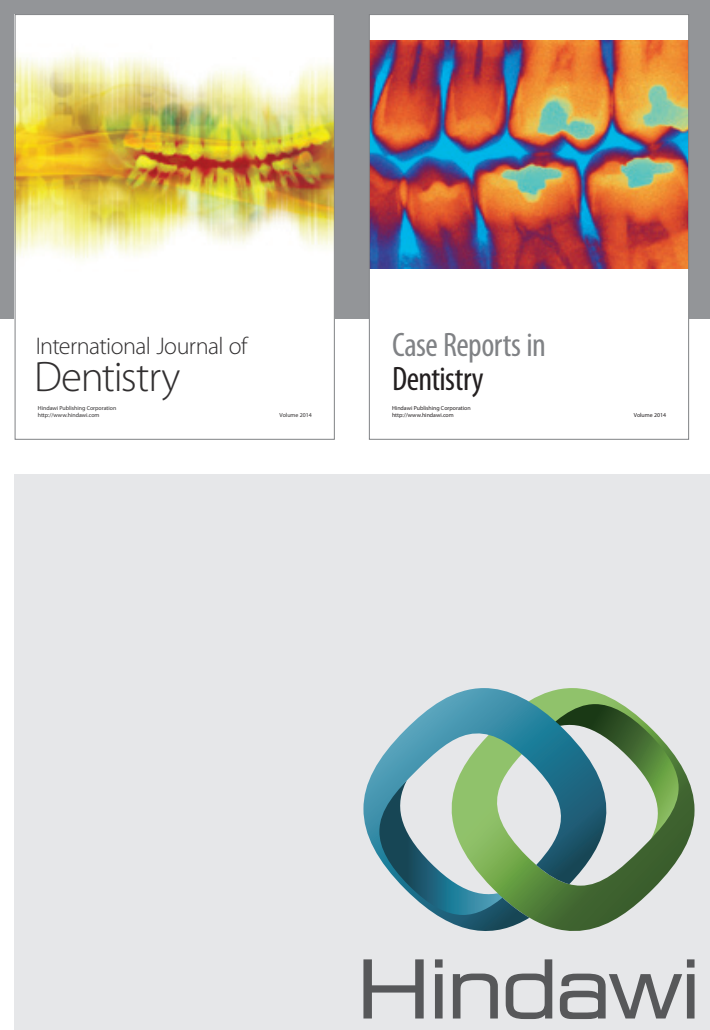

Submit your manuscripts at

http://www.hindawi.com
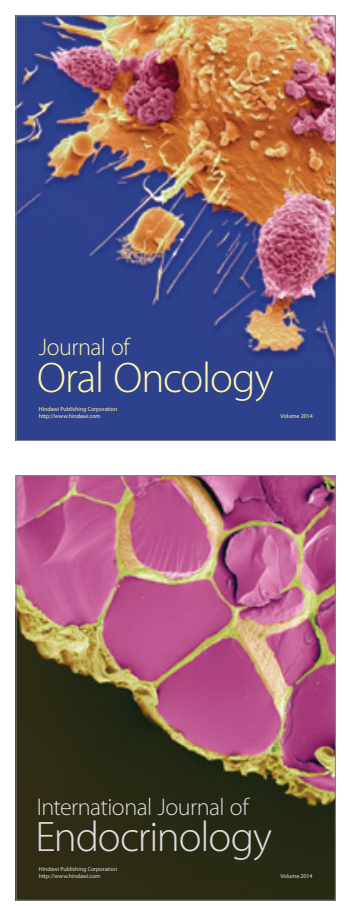
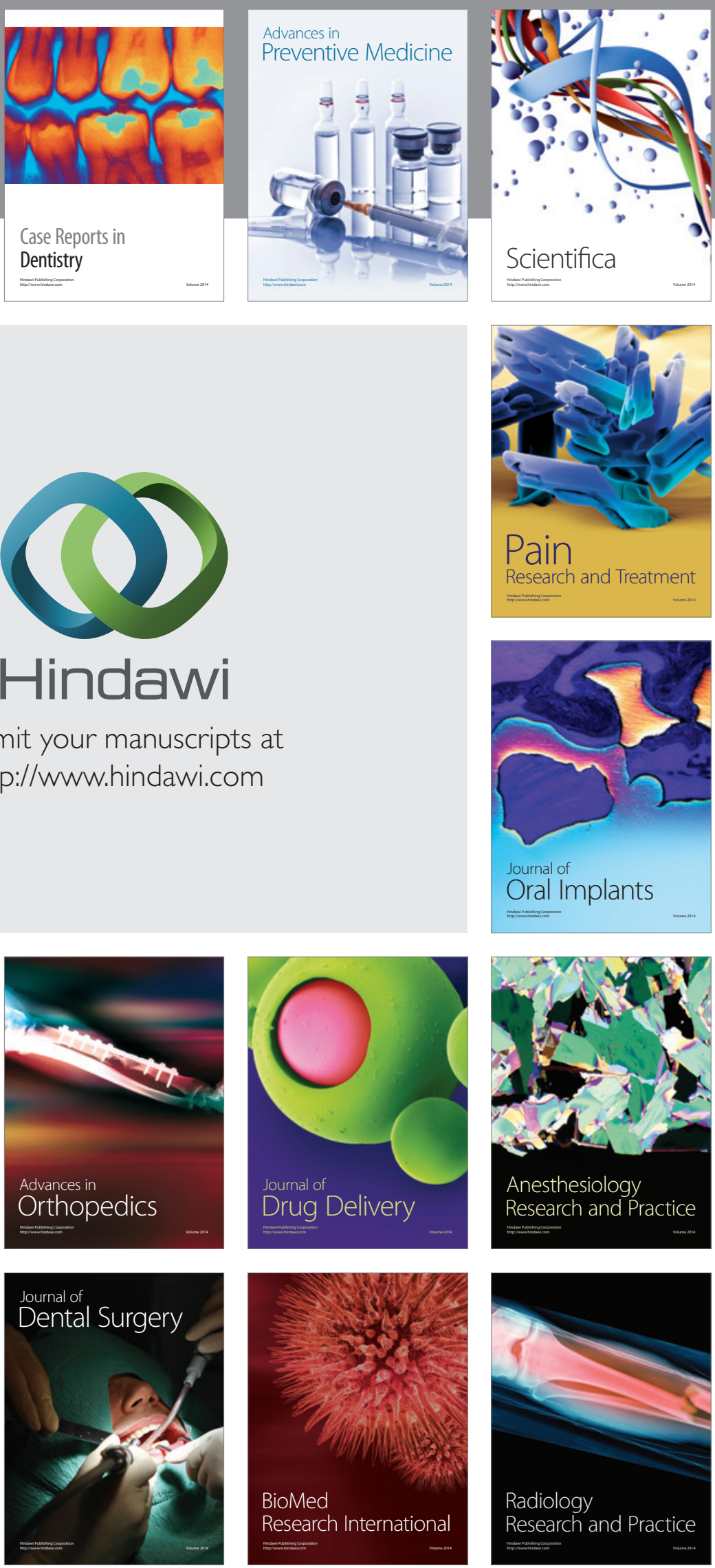